\title{
Record-Setting Usage and New Technological Opportunities
}

\section{Methodologies in this Issue}

A variety of methodologies from several different US departments of family medicine and one School for Rural Public Health ${ }^{1}$ highlight our research articles this issue. Two studies report new findings from analyses of large national public use databases. In the first study, Lutfiyya et $\mathrm{al}^{2}$ used the National Survey of Children's Health data to reveal that poverty is associated with higher childhood body mass index through influences of unsafe neighborhoods and less access to healthy foods; the second study examined data from the Atherosclerosis Risk in Communities Study. ${ }^{3}$ Other methodologies include an observational study, ${ }^{4}$ focus groups of primary care physicians, ${ }^{5}$ and a cross national border study of depression. ${ }^{1}$ These articles include new insights on common problems, ${ }^{6}$ uncommon presentations of common illnesses, ${ }^{7}$ and uncommon problems presenting as common symptoms. ${ }^{8}$ Two of 4 case reports are from US military family medicine programs. ${ }^{6,8}$

Perhaps the most fascinating new idea in this issue is from Matheson et $\mathrm{al}^{3}{ }^{3}$ who report that hay fever or allergies may be associated with stroke and postulate that inflammation is the likely reason. Many physicians are probably unaware of the potential association of cefdinir with "bloody stools."

And we have more research that can improve clinical practice: Hueston et $\mathrm{a}^{10}$ identified that any prenatal care for teens is more important than it is to get their care early in pregnancy, ie, there is no clear optimal time to start prenatal care. Baik et $\mathrm{al}^{5}$ present how experienced family physicians discuss their process of becoming comfortable recognizing depression in practice. Dallo et $\mathrm{al}^{11}$ studied physician variation in glucose test ordering practices by diabetes risk factors. Johnson and Weiss ${ }^{4}$ work to identify methods to quickly assess literacy in the clinical practice.

For the less common presentation of a common illness, Lyme disease can present as multiple ery-

Conflict of interest: The authors are editors and staff of the 7ABFM. thematous patches rather than the classic expanding erythema migrans lesion. ${ }^{7}$ Abdominal pain can actually be portal vein thrombosis associated with hepatic disease or inherited thrombogenic conditions. ${ }^{8}$ Acute psychosis from bupropion is a rarely reported condition, particularly in a young woman without a history of mental illness. ${ }^{6}$ Wilkinson and Cerreto $^{12}$ remind us of 3 health issues with particular salience for women with intellectual disabilities-osteoporosis, menstrual problems, and contraception-which may require more diligence for detection and care. They also provide helpful ideas on how to make screening procedures less stressful for these patients.

\section{JABFM Update}

Filled with both record-setting usage and new technological opportunities, the first quarter of 2008 has been an exciting period for the Fournal of the American Board of Family Medicine ( $7 A B F M)$. Some of our recent highlights include:

- In February 2008, we had approximately 69,000 distinct e-mail addresses enrolled for e-mail alerts. Go to the $7 A B F M$ website (www.jabfm. org) to sign up to receive any of a variety of e-mail alerts, including notification when a new issue is online, the table of contents for each new issue with hyperlinks to articles, future tables of contents which list articles in upcoming issues, and/or announcements from the $7 A B F M$ publisher.

- Request for content continues to increase with 136,883 requests in January 2008, creating the most successful month for content usage. This includes all requests for the home page, table of contents, searches, abstracts, and full-text HTML and PDF files.

- The $7 A B F M$ and more than 200 other journals from HighWire Press and the Nature Publishing Group are participating in Stanford University's Structured Digital Abstract Consortium pilot project, which will build a new type of search engine to aid researchers to more efficiently 
search biomedical literature. Please go to http:// www.sdabstract.org/ to learn more about this interesting project.

The Editors and staff of the $\mathcal{F} A B F M$ would like to thank our readers, authors, and supporters for a great start to 2008 .

Marjorie A. Bowman, MD, MPA

Anne Victoria Neale, PhD, MPH

Philip Lupo, MLIS

\section{References}

1. Mier N, Bocanegra-Alonso A, Zhan D, et al. Clinical depressive symptoms and diabetes in a binational border population. J Am Board Fam Med 2008; 21(3):223-233.

2. Lutfiyya MN, Garcia R, Dankwa CM, Young T, Lipsky MS. Overweight and obese prevalence rates in African American and Hispanic children: An analysis of data from the 2003-2004 National Survey of Children's Health. J Am Board Fam Med 2008; 21(3):191-199.

3. Matheson EM, Player MS, Mainous AG, King DE, Everett CJ. The association between hay fever and stroke in a cohort of middle aged and elderly adults. J Am Board Fam Med 2008; 21(3)4:179-183.

4. Johnson K, Weiss BD. How long does it take to assess literacy skills in clinical practice?. J Am Board Fam Med 2008; 21(3):211-214.

5. Baik SY, Bowers BJ, Oakley LD, Susman JL. What comprises clinical experience in recognizing depression?: the primary care clinician's perspective. J Am Board Fam Med 2008; 21(3):200-210

6. Bailey J, Waters S. Acute psychosis after bupropion treatment in a healthy 28-year-old woman. J Am Board Fam Med 2008; 21(3):244-245.

7. Salzman BE, Stonehouse A, Studdiford J. Late diagnosis of early disseminated Lyme disease: perplexing symptoms in a gardener. J Am Board Fam Med 2008; 21(3):234-236.

8. Ferguson JL, Hennion DR. Portal vein thrombosis: an unexpected finding in a 28-year-old male with abdominal pain. J Am Board Fam Med 2008; 21(3): 237-243.

9. Graves R, Weaver SP. Cefdinir-associated "bloody stools" in an infant. J Am Board Fam Med 2008; 21(3):246-248.

10. Hueston WJ, Quattlebaum RG, Benich JJ. How much money can early prenatal care for teen pregnancies save?: A cost-benefit analysis. J Am Board Fam Med 2008; 21(3):184-190

11. Dallo FJ, Weller SC, Cass AR. Variations in glucose test ordering practices by diabetes risk factors. J Am Board Fam Med 2008; 21(3):249-250.

12. Wilkinson JE, Cerreto MC. Primary care for women with intellectual disabilities. J Am Board Fam Med 2008; 21(3):215-222. 